\title{
Erratum to: Submerged Gas Jet Penetration: A Study of Bubbling Versus Jetting and Side Versus Bottom Blowing in Copper Bath Smelting
}

\author{
JOËL P.T. KAPUSTA (1) ${ }^{1,2}$ \\ 1.-BBA Inc., 2020 Robert-Bourassa Blvd., Suite 300, Montréal, QC H3A 2A5, Canada. 2.-e-mail: \\ joel.kapusta@bba.ca
}

\section{Erratum to: JOM, Vol. 69, No. 6, 2017,} DOI: $10.1007 / \mathbf{s 1 1 8 3 7 - 0 1 7 - 2 3 3 6 - 4}$

Equation 6 appeared incorrectly in the original version of this article. It is corrected below (Eq. 6):

$$
M_{\text {exp } .}=\sqrt{\left[\left(\frac{P_{\text {exit }}}{P_{\text {metal. }}}\right)^{(k-1) / k}\left(\frac{k+1}{2}\right)-1\right] \frac{2}{k-1}}
$$

